\title{
Prevention of Biliary Leaks by Biliary Drainage after Hydatid Liver Surgery
}

\author{
Cuneyt Kayaalp \\ Department of Gastrointestinal Surgery, Turkey Yuksek Ihtisas Hospital, Ankara, Turkey
}

Dear Sir,

I read with great interest the article about the surgical treatment of hydatid disease of the liver by Silva et al. [1], and I thank them for their study. They reported $50 \%$ cystobiliary communication rates in hydatid liver cysts, and their study recommended biliary system drainage in those cases. I completely agree with the authors that the rates of cystobiliary communications in the literature are underreported, and we found a rate of $37 \%$ [2]. However, I am worried about the routine biliary drainage that may increase postoperative morbidity and hospital stay. Obliteration of the cavity (especially by omentoplasty) is a good alternative for prevention of postoperative biliary complications $[3,4]$. In the past, we preferred biliary drainage only in the cases of common bile duct exploration for hydatid jaundice [5]. Nowadays, this procedure has decreased with the opportunity of using preoperative endoscopic retrograde cholangiopancreatography as well. I believe that routine biliary drainage may be an aggressive approach for the hydatid liver cysts with cystobiliary communication.

The second point is using methylene blue for the detection of cystobiliary communications. In an experimental study in rats, we compared the effects of vital dyes (methylene blue and fluorescein) with normal saline on hepatobiliary system and found better liver function tests and histopathological results with normal saline and fluorescein than methylene blue [6]. I prefer normal saline instead of vital dyes for detection of cystobiliary communications through the common bile duct. Dyes also have the disadvantage of coloring the surgical area that make it difficult to identify the biliary orifice, and especially if there is more than one orifice.
I did not understand the reason of routine cholecystectomy in hydatid liver surgery and lastly, the term of 'anti-scolicidal' is, I think, a misprint.

Thank you very much.

\section{References}

1 Silva MA, Mirza DF, Bramhall SR, Mayer AD, McMaster P: Treatment of hydatid disease of the liver. Dig Surg 2004;21:227-234.

2 Kayaalp C, Bzeizi K, Demirbag AE, Akoglu M: Biliary complications after hydatid liver surgery: incidence and risk factors. J Gastrointest Surg 2002;6:706-712.

3 Dziri C, Paquet JC, Hay JM, Fingerhut A, Msika S, Zeitoun G, Sastre B, Khalfallah T: French Associations for Surgical Research. Omentoplasty in the prevention of deep abdominal complications after surgery for hydatid disease of the liver: a multicenter, prospective, randomized trial. J Am Coll Surg 1999;188:281-289.

4 Kayaalp C, Sengul N, Akoglu M: Importance of cyst content in hydatid liver surgery. Arch Surg 2002;137:159-163.

5 Elbir OH, Gundogdu H, Caglikulekci M, Kayaalp C, Atalay F, Savkilioglu M, Seven C: Surgical treatment of intrabiliary rupture of hydatid cysts of liver: comparison of choledochoduodenostomy with T-tube drainage. Dig Surg 2000; 18:289-293.

6 Kayaalp C, Kirimlioglu V, Yilmaz S, Gundogdu H, Akoglu M: Effect of methylene blue and fluorescein on liver and biliary system. Clin Sci Doctor 1999;5:344-346.

\section{Reply}

Dear Sir,

Many thanks for your interest in our paper on the treatment of hydatid disease. In answer to your question you will see, how- ever, that without question in our own series the morbidity and therefore hospital stay was significantly longer in those patients who had cystobiliary communications and did not receive biliary decompression. I accept that there maybe alternatives to the surgical approach used in our series of patients and this could include transcystic biliary decompression or the insertion of an operative transampullary stent. I do not believe that omentoplasty would prevent a bile leak.

I am also not aware of any evidence in the literature to suggest that methylene blue when used in the biliary system in human has any adverse effect. Certainly in our own series we have used methylene blue both within this cohort of patients and within other cohorts of patients without any problems. It is our own impression that methylene blue helps identify cystobiliary communication and is preferential to saline, although of course this is individual surgeon preference.

The reason for routine cholecystectomy in our patients is that these patients are being operated on through a right upper quadrant incision. There is good evidence that upper GI procedures lead to an increase in the instance of gallstones, the median age of our patients is forty one years and the presence of a right upper quadrant incision makes subsequent laparoscopic cholecystectomy almost impossible. We have had no morbidity associated with cholecystectomy in this cohort and I believe that the longterm risks of cholecystectomy are extremely small.

Mr. S.R. Bramhall, MD, FRCS

Consultant Hepatobiliary and

Transplant Surgeon

\section{KARGER}

Fax +4161306 1234 E-Mail karger@karger.ch www.karger.com
Dr. Cuneyt Kayaalp

Kenedy caddesi, Yalim sokak

8/6 Kavaklidere, TR-06660 Ankara (Turkey)

Tel. +90 312419 7330, Fax +90 3123124120

E-Mail cuneytkayaalp@hotmail.com 